
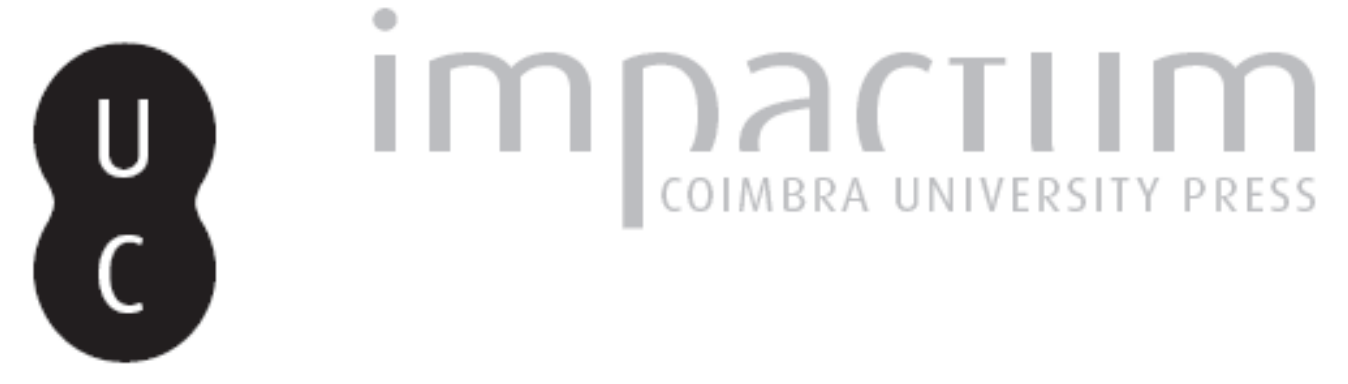

\title{
Risco da construção do conhecimento de alunos num ambiente térmico quente
}

Autor(es): $\quad$ Talaia, Mário; Silva, Marta

Publicado por: $\begin{aligned} & \text { Associação Portuguesa de Riscos, Prevenção e Segurança; Imprensa } \\ & \text { da Universidade de Coimbra }\end{aligned}$

URL persistente:

URI:http://hdl.handle.net/10316.2/38070

DOI:

DOI:http://dx.doi.org/10.14195/1647-7723_22_17

Accessed : $\quad$ 26-Apr-2023 09:55:23

A navegação consulta e descarregamento dos títulos inseridos nas Bibliotecas Digitais UC Digitalis, UC Pombalina e UC Impactum, pressupõem a aceitação plena e sem reservas dos Termos e Condições de Uso destas Bibliotecas Digitais, disponíveis em https://digitalis.uc.pt/pt-pt/termos.

Conforme exposto nos referidos Termos e Condições de Uso, o descarregamento de títulos de acesso restrito requer uma licença válida de autorização devendo o utilizador aceder ao(s) documento(s) a partir de um endereço de IP da instituição detentora da supramencionada licença.

Ao utilizador é apenas permitido o descarregamento para uso pessoal, pelo que o emprego do(s) título(s) descarregado(s) para outro fim, designadamente comercial, carece de autorização do respetivo autor ou editor da obra.

Na medida em que todas as obras da UC Digitalis se encontram protegidas pelo Código do Direito de Autor e Direitos Conexos e demais legislação aplicável, toda a cópia, parcial ou total, deste documento, nos casos em que é legalmente admitida, deverá conter ou fazer-se acompanhar por este aviso.

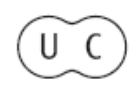




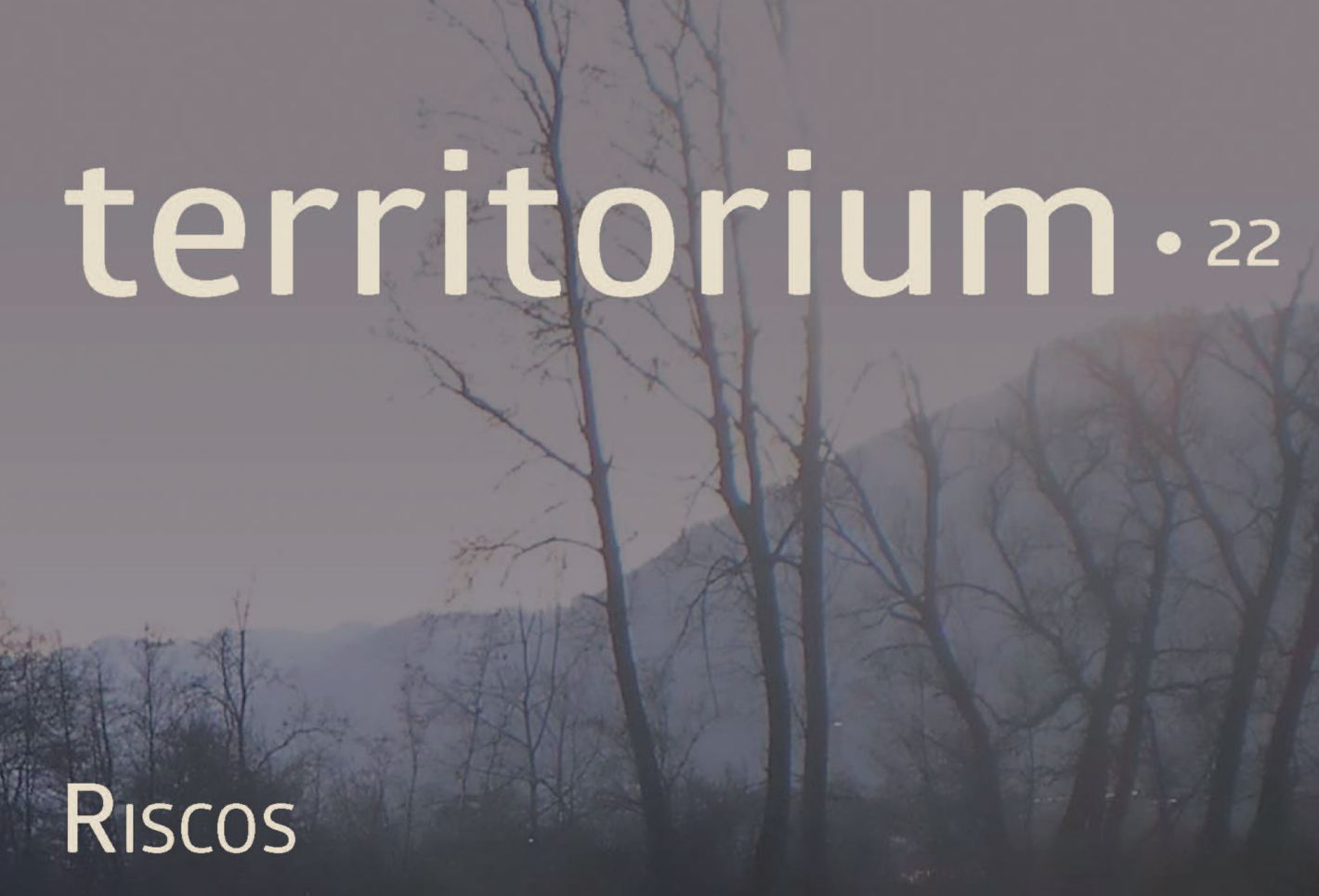

\section{TERRITÓRIOS DE CONVERGÊNCIA}

- Imprensa da Universidade de Coimbra Associação Portuguesa de:Riscos, Prevenção e Segurança 


\title{
RISCO DA CONSTRUÇÃO DO CONHECIMENTO DE ALUNOS NUM AMBIENTE TÉRMICO QUENTE*
}

RISK OF THE CONSTRUCTION OF KNOWLEDGE OF STUDENTS IN HOT THERMAL ENVIRONMENT

Mário Talaia

Departamento de Física da Universidade de Aveiro mart@ua.pt

Marta Silva

Departamento de Física da Universidade de Aveiro martaacsilva@hotmail.com

\section{RESUMO}

Começa a ser aceite que o ambiente térmico influencia a construção de conhecimento de alunos e por isso afeta o ensino e a aprendizagem. Neste trabalho é mostrado como o risco da construção de conhecimento de alunos aumenta para ambientes térmicos quentes. Os resultados obtidos mostram que o desenvolvimento de competências e a avaliação registada são condicionados pelo ambiente térmico e que é possível avaliar o risco quando as condições térmicas do interior de uma sala de aula divergem da zona de conforto.

Palavras-chave: Ambiente térmico, sensação térmica, educação ambiental, ensino e aprendizagem, construção conhecimento.

\begin{abstract}
The thermal environment influences the construction of knowledge of students and affects the teaching and learning. In this work it is shown how the risk of students' knowledge construction is increasing for hot thermal environments. The results have shows that the development of skills and evaluation registered are influenced by the thermal environment and that it is possible to assess the risk when the thermal conditions of the inside of a classroom diverge from the comfort zone.
\end{abstract}

Keywords: Thermal environment, thermal sensation, environmental education, teaching and learning.

\section{RESUMEN}

Riesgo de construcción del conocimiento de los estudiantes en medio ambiente caliente - El medio ambiente caliente influye en la construcción del conocimiento de los estudiantes y afecta a la enseñanza y el aprendizaje. En este trabajo se muestra cómo el riesgo de construcción del conocimiento de los estudiantes aumenta en entornos termales calientes. Los resultados han mostrado que el desarrollo de habilidades y la evaluación registrada están influenciadas por el medio ambiente térmico y que es posible evaluar el riesgo cuando las condiciones térmicas del interior de un salón de clases divergen de la zona de confort.

Palabras clave: Medio ambiente térmico, sensación térmica, educación ambiental, enseñanza y aprendizaje, construcción del conocimiento.

\section{RÉSUMÉ}

Risque de la construction de la connaissance pour étudiantes pour dans un environnement thermique chaud - L'environnement thermique influe sur la construction de la connaissance des étudiants et affecte l'enseignement et l'apprentissage. Dans ce travail, il est montré comment le risque de construction de connaissances augmente pour environnements thermiques chaud. Les résultats ont montré que le développement de compétences et l'évaluation enregistrés sont influencés par l'environnement thermiques.

Mots-clé: Environnement thermique, sensation thermique, éducation environnementale, enseignement et apprentissage.

* O texto deste artigo corresponde a uma comunicação apresentada no III Congresso Internacional, I Simpósio Ibero-Americano e VIII Encontro Nacional de Riscos, tendo sido submetido em 27-01-2015, sujeito a revisão por pares a 30-04-2015 e aceite para publicação em 23-07-2015.

Este artigo é parte integrante da Revista Territorium, $n .{ }^{\circ} 22,2015,{ }^{\circ}$ RIscos, ISSN: 0872-8941. 


\section{Introdução}

A problemática de ambiente térmico permite conhecer se uma pessoa se encontra em conforto térmico num espaço, como por exemplo no interior de um compartimento de uma casa, nos locais de trabalho ou de estudo, ou no exterior de um edifício.

É aceite que a concentração e a produtividade de uma pessoa é fortemente condicionada pelo conforto térmico. O desconforto térmico é um indicador importante para a saúde, porque é o primeiro sintoma que alerta para as condições ambientais não serem adequadas (M. Morgado et al., 2015; I. Tavares et al., 2015).

A ASHRAE - American Society of Heating, Refrigerating and Air-Conditioning Engineers (2004) desenvolveu um sistema para quantificar o conforto térmico onde, tendo em consideração a temperatura e a humidade relativa do ar, ficou definido o "espaço climático" no qual $90 \%$ das pessoas se sentem confortáveis. No entanto, e com base em inúmeras investigações nesta área, os especialistas chegaram à conclusão que o conforto térmico não é tão linear, uma vez que a mesma pessoa se pode sentir confortável em condições térmicas diferentes, consoante as características do edifício: num edifício de serviços que depende de sistemas artificiais para criar as condições de conforto (o que, em Portugal, é o caso na grande maioria dos edifícios de serviços, construídos para esse fim, desde os anos 90), a tolerância das pessoas às amplitudes térmicas é muito menor do que se as mesmas pessoas se encontrarem num espaço interior "passivo" que não dependa de sistemas artificiais para alcançar condições de conforto térmico. Assim, a temperatura e a humidade relativa que geram condições confortáveis em espaços interiores é variável e influenciada pela temperatura média do exterior.

É bom recordar as palavras escritas pelo professor Doutor Fernando Rebelo, do Departamento de Geografia da Universidade de Coimbra, aquando do lançamento do livro de Homenagem no programa da cerimónia de Jubilação, ao citar o trabalho publicado por M. Talaia (2013) “... ao ler a parte relativa ao ambiente térmico em sala de aula, por exemplo, lembrei-me de um caso que soube ter acontecido numa grande sala de aula, com muitos vidros que a faziam bonita, mas que a transformavam numa estufa de calor - em certo dia, à tarde, vários alunos desmaiaram numa sequência que levou à suspensão da aula ...".

As palavras de tão ilustre pessoa, no Ensino e Ciência em Portugal e no Estrangeiro, mostram bem a relevância do risco na problemática do ambiente térmico na vertente ensino e aprendizagem.

Segundo J. Goldemberg e O. Lucon (2007), os problemas energéticos fazem parte do quotidiano do ser humano.
Nos currículos de Ciências destacam-se ideias associadas a conceções substancialistas de energia, notoriamente presentes noutros âmbitos, que aparentemente integram formas dominantes de pensamento, passando a utilizar-se indiscriminadamente $(N$. Souza e R. Justi, 2011). No processo de implementação do Desenvolvimento Sustentável a Educação é, de facto, a principal ferramenta que se dispõe para atingir o paradigma do Desenvolvimento Sustentável. A UNESCO ao instituir a Década das Nações Unidas da Educação para o Desenvolvimento Sustentável (2005-2015) revela preocupações com o desenvolvimento e pretende, deste modo, melhorar a qualidade do ensino, facilitar a troca de experiências entre os diversos atores envolvidos e fazer com que haja uma maior atenção pública relativa a este assunto.

D. Tilbury (2011) recomenda que partir de questões problema relacionadas com sustentabilidade se promova ABRP (Aprendizagem Baseada na Resolução de Problemas) para os alunos desenvolverem literacia em sustentabilidade, perspetivando soluções e ações alternativas, planeando-as, implementando-as, refletindo sobre elas e avaliando-as.

A Ergonomia aparece como um conjunto de disciplinas que permite estudar a organização do trabalho (intelectual ou produtivo) no qual existe interações entre seres humanos e os sistemas que os envolvem. o principal objetivo da ergonomia é desenvolver e aplicar técnicas de adaptação do ser humano visando a otimização do seu bem-estar. Com o desenvolvimento de pesquisas em torno da Ergonomia surgiu a necessidade de avaliar o efeito do "clima" no posto ou local de trabalho (intelectual ou produtivo) e no ser humano (E. Kruger et al., 2001). As primeiras investigações que se debruçaram no estudo desta relação surgiram no século XIX e tinham como finalidade incrementar os níveis de produtividade industrial (D. Markov, 2002). Na década de 50 do século XX, a ASHVE (American Society for Heating and Ventilation Engineers) promove a primeira sistematização de pesquisas empíricas e analíticas sobre ambiente e conforto térmico.

O estudo do conforto térmico tem uma forte importância económica. 0 controlo das variáveis termohigrométricas permite a otimização do ambiente térmico e consequentemente um incremento nos níveis intelectual ou produtivo. Várias pesquisas realizadas em campo têm sido desenvolvidas de forma a demonstrar a relação entre o conforto térmico e o desempenho do trabalhador/ estudante (D. Wyon, 2010; Morgado et al., 2015). Embora os resultados destas atividades experimentais não tenham conduzido a conclusões definitivas, mostraram claramente a tendência do desconforto, proporcionado por ambientes quentes ou frios, reduzir o desempenho intelectual ou produtivo. 
No entanto, é necessário enfatizar o carácter social do estudo desta temática. O conforto térmico não deverá ser analisado tendo como "pano" de fundo uma perspetiva economicista. O conforto térmico é antes de mais um problema de saúde pública e deverá ser analisado desta forma. Daí ser considerado um problema social, económico e político.

Segundo P. Fanger (1972), o conforto térmico envolve variáveis físicas ou ambientais e, também, variáveis subjetivas ou pessoais. Não é possível que um grupo de pessoas sujeitas ao mesmo ambiente, ao mesmo tempo, esteja todo ele satisfeito com as condições térmicas do mesmo, devido às características individuais das pessoas. As variáveis físicas que afetam o conforto térmico são: temperatura do ar, temperatura média radiante, humidade relativa do ar e velocidade relativa do ar. As variáveis subjetivas envolvidas nas análises, são: atividade desempenhada pela pessoa (indicativa da quantidade de calor produzida pelo organismo, e apresentada sob a forma de taxa metabólica) e o vestuário usado pela pessoa (indicativa da resistência térmica oferecida às trocas de calor entre o corpo e o ambiente, e apresentada sob a forma de isolamento térmico das roupas).

W. Howell e C. S. Stramiler (1981) referem que além das variáveis anteriormente indicadas existem variáveis psicológicas a serem levadas em consideração nos estudos de conforto térmico nomeadamente a temperatura percecionada pela pessoa, o sentimento próprio de se sentir mais aquecida ou mais refrescada do que outras pessoas, a tolerância percebida ou tolerabilidade e o ajustamento ou adaptação. Adicionalmente os autores indicam outras quatro variáveis psicológicas, nomeadamente, decréscimo de "performance", decréscimo de conforto, decréscimo de energia física e decréscimo de afeto.

Atualmente, quando se fala do desenvolvimento cognitivo e dos processos de ensino e aprendizagem devem-se considerar aspetos importantes relacionados com a motivação, os estímulos do meio (ambiente envolvente da pessoa), as relações sociais e a educação recebida, entre outros (C. Coll et al., 2005). Separando o fenómeno da educação como algo de natureza essencialmente social e destacando-se as práticas educativas encontradas na educação formal pode-se perceber uma preocupação constante com elementos, novos e antigos, que interferem direta e indiretamente nesse fenómeno. Um desses fatores diz respeito ao ambiente de ensino, à sua organização e às variáveis que podem influenciar positiva e negativamente a aprendizagem.

É sabido que a preocupação com o desempenho térmico nas escolas públicas tem tido pouca importância. A experiência de um autor, deste artigo, como orientador da prática pedagógica durante muitos anos, na formação de professores em diferentes escolas da região centro de Portugal mostrou que há inúmeras salas de aula que não registam condições de ambiente térmico confortável para o ensino e aprendizagem. A maioria das edificações escolares, em Portugal, apresenta partidos arquitetónicos e sistemas construtivos mais ou menos padronizados, moldados da mesma forma em todo o país, sendo a mesma ideia de projeto construída, muitas vezes, em vários locais do país, sem ter em conta as características do tipo de clima da região.

Todos estes fatores aliados conferem a uma grande parte das edificações escolares públicas um espaço que não satisfaz as necessidades básicas de conforto térmico. Certamente estas condições interferem negativamente na motivação, concentração e avaliação dos alunos. Desta forma, é necessário que numa arquitetura escolar se tenha em conta as necessidades de conforto térmico, de forma a proporcionar um ambiente agradável e que favoreça o ensino e aprendizagem (M. C. J. A. Nogueira e J. S. Nogueira, 2003).

A. Rebelo et al. (2008) mostraram, ainda, que o ambiente térmico em salas de aula é um dos fatores que condiciona o processo de aprendizagem em qualquer dos graus de ensino. Os autores mostraram a forte influência da oposição solar ao longo do dia nas condições de conforto nas salas de aula.

D. Wyon (2010) relacionou o conforto térmico com o ensino e aprendizagem de alunos e apresentou dados registados em salas de aula de duas escolas na Dinamarca, envolvendo cerca de 300 alunos. Os resultados obtidos mostraram uma diminuição da avaliação de 3,5\% dos alunos por cada ${ }^{\circ} \mathrm{C}$ de aumento de temperatura interior da sala de aula. $O$ autor mostrou, ainda, que os resultados confirmam a dimensão dos efeitos do ambiente térmico no desempenho, ou seja para $+10^{\circ} \mathrm{C}$ verifica-se uma diminuição de cerca de 35\% no trabalho escolar.

Este trabalho pretende mostrar que o ambiente térmico quente de uma sala de aula aumenta o risco de afetação da aprendizagem e consequente avaliação de alunos não apenas através da temperatura do ar, mas através da relação entre parâmetros termohigrométricos.

\section{Materiais e Métodos}

0 estudo, realizado em sala de aula, utilizou a metodologia de investigação-ação, de carácter empírico, recorrendo a uma metodologia mista, onde foram utilizados métodos quantitativos e métodos qualitativos de recolha de dados.

A investigação decorreu entre 14 de Maio a 5 de Junho de 2013, para um ambiente de sala de aula considerado de ambiente quente, tendo participado 41 alunos, de duas turmas do $8^{\circ}$ ano de escolaridade de uma escola de 
Ensino Básico da região centro de Portugal. Os alunos, 18 do sexo feminino e 23 do sexo masculino, apresentavam idades de 13 anos (39) e 14 anos (2). Neste estudo os alunos são identificados por $\mathrm{Ai}$ com $\mathrm{i}=1$ a 41 .

Ao longo da implementação dos métodos em sala de aula, foram propostas aos alunos diferentes atividades, através da aplicação de fichas de trabalho/questões-aula. Estas questões-aula eram sobre conteúdos que estavam a ser leccionados e tiveram como objetivo avaliar o risco do desenvolvimento de competências relativo à construção do conhecimento dos conteúdos lecionados na aula, e eram aplicadas sempre que se considerava oportuno. Os alunos não tinham conhecimento prévio da sua realização. Nas questões-aula era apresentada uma escala térmica de cores onde os alunos selecionavam a posição na cor correspondente à sua sensação de conforto térmico que sentiam aquando da realização da ficha de trabalho.

Os parâmetros termohigrométricos foram registados usando um psicrómetro construído pelos alunos. Estes valores permitiram prever a sensação térmica do interior da sala de aula.

Para se determinar a sensação térmica real sentida pelos alunos foi usada uma escala térmica de cores desenvolvida por M. Talaia e F. Rodrigues (2008), como se mostra no lado esquerdo da fig. 1. Posteriormente, através de uma escala linear de -3 (extremidade da cor azul mais escura) a +3 (extremidade da cor vermelha mais escura) determinou-se o valor correspondente, e em décimos, da sensação térmica real na escala ISO 7730 (2005), conforme se indica no lado direito da fig. 1.

O conjunto de dados registados foi tratado usando o programa SPSS. Foram usados vários índices, nomeadamente o índice EsConTer, o índice de temperatura e humidade (ITH), o índice de Calor (IC) e o índice PPD.
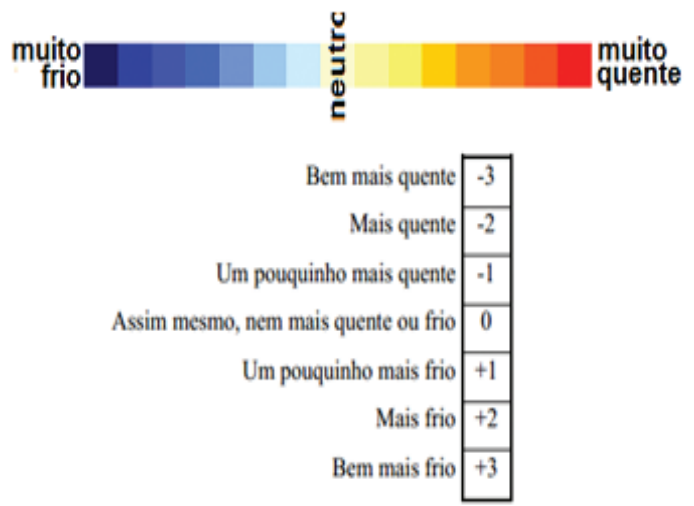

Fig. 1 - Escala se sensação térmica (M. Talaia e F. Rodrigues, 2008), e escala ISO 7730 (2005).

Fig. 1 - Thermal sensation of scale (M. Talaia and F. Rodrigues, 2008), and ISO 7730 scale (2005).
Para a determinação do índice de temperatura e humidade (ITH), que foi modificado por S. Nieuwolt (1977), foi usada a expressão

$$
\mathrm{ITH}=0,8 \mathrm{~T}+\mathrm{T}(\mathrm{U} / 500)
$$

em que $\mathrm{T}\left({ }^{\circ} \mathrm{C}\right)$ representa a temperatura do ar e $\mathrm{U}(\%)$ a humidade relativa do ar.

Os valores de $\mathrm{ITH}$, em ${ }^{\circ} \mathrm{C}$, foram interpretados, em termos de sensação térmica, através da adaptação efetuada por M. Talaia et al. (2013), tal como se mostra na TABELA I.

TABELA I - Sensação térmica com base no ITH.

TABLE I - Thermal sensation ITH.

\begin{tabular}{c|c}
\hline ITH & Sensação térmica \\
\hline ITH $<8$ & zona demasiado fria \\
\hline $\begin{array}{c}8 \leq \text { ITH }<21 \\
21 \leq \text { ITH } \\
<24\end{array}$ & zona com necessidade aquecimento \\
\hline $\begin{array}{c}24 \leq \text { ITH } \\
<26\end{array}$ & CONFORTO TÉRMICO \\
\hline $26 \leq$ ITH & zona demasiado quente \\
\hline
\end{tabular}

O índice EsConTer, desenvolvido por M. Talaia e H. Simões (2009), é calculado a partir da expressão

$$
\text { EsConTer }=-3,75+0,103(T+\mathrm{Tw})
$$

em que T representa a temperatura do $\operatorname{ar}\left({ }^{\circ} \mathrm{C}\right)$ e Tw a temperatura do termómetro húmido $\left({ }^{\circ} \mathrm{C}\right)$.

O EsConTer determina um valor da escala sétima de sensação térmica e é de fácil cálculo matemático. Sendo o valor de EsConTer na gama de -3 (ambiente térmico muito frio) $a+3$ (ambiente térmico muito quente) facilmente é interpretado o ambiente em termos de conforto térmico.

A percentagem de insatisfeitos que se prevê para um ambiente térmico, foi calculada pela aplicação do índice PPD que determina a percentagem de insatisfeitos de acordo com a norma ISO 7730 (2005). Na expressão original o PMV (voto médio de satisfação) é substituído pelo valor de EsConTer por usar a mesma escala térmica ASHRAE (2004), como se indica na expressão

$$
\text { PPP }=100-95 \mathrm{e}^{-(0,03353 \mathrm{ESCOnTer} 4+0,2179 \mathrm{ESConTer} 2)}
$$

A fig. 2 mostra a linha da sensação térmica em termos de satisfação/insatisfação, quando é usado o índice EsConTer (M. Talaia e H. Simões, 2009).

Para o índice de Calor, a humidade relativa do ar não é considerada como parâmetro importante para determinar IC (R.S. Nobrega e T.V.S Lemos, 2011). 0 
seu cálculo deve ser considerado quando o valor da temperatura for superior a $20^{\circ} \mathrm{C}$, e é dado por,

$$
I C=(5 / 9)\left(a+b T+c U+d T U+e T^{2}+f U^{2}+g T^{2} U+h T U^{2}+i T^{2} U^{2}\right)
$$

onde $\mathrm{a}=-74,379 ; \mathrm{b}=2,04901523 ; \mathrm{c}=10,14333127 ; \mathrm{d}=$ $-0,22475541 ; e=-6,83783 \times 10^{-3} ; f=-5,481717 \times 10^{-2} ; g=$ $1,22874 \times 10^{-3} ; \mathrm{h}=8,5282 \times 10^{-4} ; i=-1,99 \times 10^{-6}$, e em que IC representa o índice de calor $\left({ }^{\circ} \mathrm{C}\right)$, T a temperatura do ar $\left({ }^{\circ} \mathrm{F}\right)$ e $\mathrm{U}$ a humidade relativa do ar (\%).

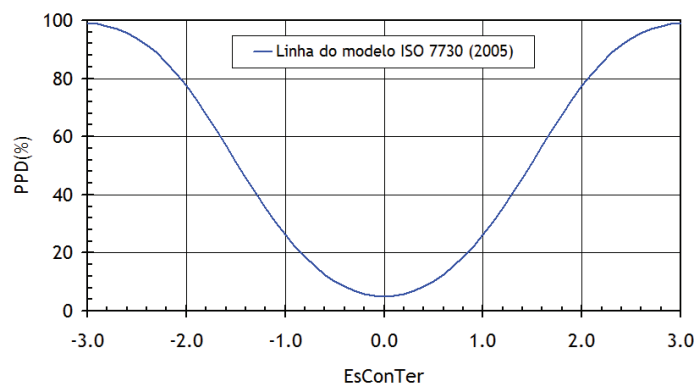

Fig. 2 - Modelo e situação de sensação de "frio" e sensação de “calor" (Fonte: adaptado ISO 7730, 2005).

Fig. 2 - Model and situation of thermal sensation "cold" and “heat" (Source: adapted ISO 7730, 2005).

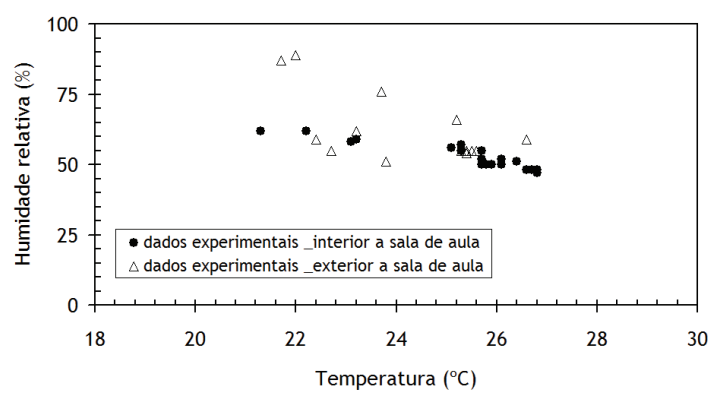

Fig. 3 - Humidade relativa em função da temperatura do ar no interior e exterior da sala de aula.

Fig. 3 - Relative humidity depending on the temperature of the air inside and outside the classroom.

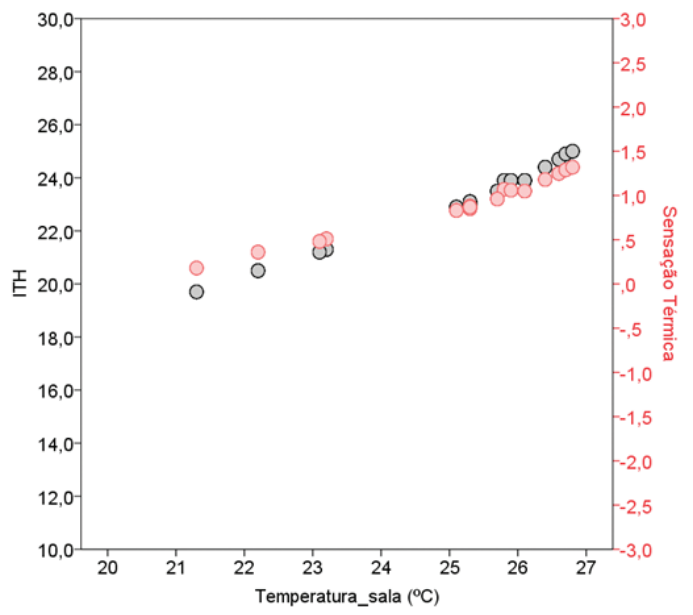

\section{Resultados e Discussão}

A fig. 3 mostra a relação entre a temperatura e a humidade relativa do ar no interior e no exterior da sala de aula para o período de observação. Os resultados obtidos estão em concordância com a teoria, ou seja, quando a temperatura do ar aumenta regista-se uma diminuição da humidade relativa do ar.

A fig. 4 mostra como o índice temperatura e humidade ITH, o índice EsConTer e o índice de calor IC variam com a temperatura interior registada na sala de aula.

A observação dos gráficos da fig. 4 mostra que há uma excelente correlação nos valores obtidos para o índice ITH, índice de Calor IC e índice EsConTer (sensação térmica), quando a temperatura do ar da sala de aula aumenta. Este resultado indicia o risco da construção do conhecimento quando a sensação térmica ultrapassa o patamar do conforto térmico (S. Nieuwolt, 1977; M. Talaia e H. Simões, 2009; ISO 7730, 2005; R. S. Nobrega e T. V. S. Lemos, 2011).

A fig. 5 mostra como o risco do aumento da sensação térmica condiciona a avaliação dos alunos, identificados por Ai com i=10 a 17 (como exemplo). Os gráficos da figura apresentam como ordenada (lado esquerdo) a Avaliação_j com j=1 a 5 representada por colunas, como ordenada (lado direito) a sensação térmica real dos alunos registada na escala térmica de cores e indicada pela linha quebrada (de cor vermelha) e a linha ponteada horizontal a sensação térmica prevista pelo índice EsConTer (de cor azul). Na abcissa são representados alguns alunos (como exemplo) por Ai em que $\mathrm{i}$ varia de 1 a 41 .

A fig. 6 mostra os resultados para os alunos, em termos de Avaliação_j.

A observação dos gráficos da fig. 6 mostra para cada Avaliação_j e para cada aluno, os resultados obtidos e de que modo são influenciados pela sensação térmica sentida. Na prática, como seria esperado, quando a

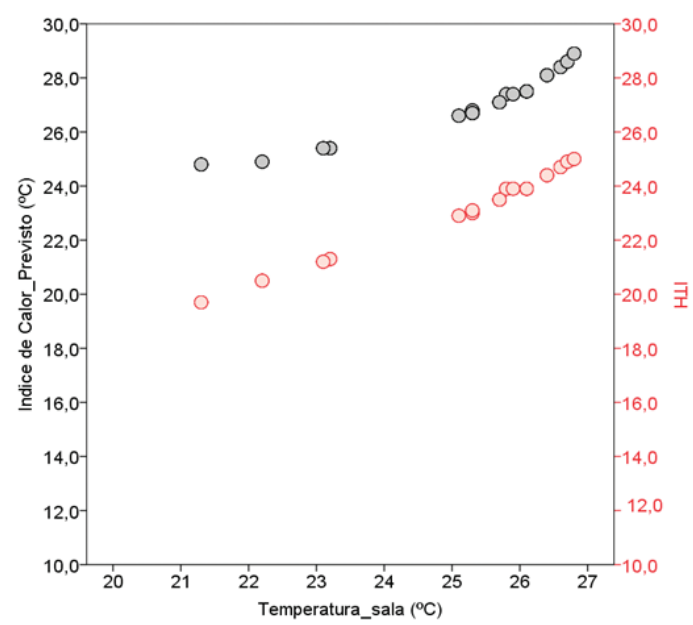

Fig. 4 - ITH, sensação térmica (EsConTer) e Índice de Calor "versus" temperatura do ar.

Fig. 4 - ITH, thermal sensation (EsConTer) and Heat Index "versus" air temperature. 
sensação térmica se situa na gama de conforto térmico, os resultados são positivos. Quando a sensação térmica sentida pelo aluno suscita um ambiente ligeiramente quente $(+1.0)$ a quente $(+2.0)$ os resultados, no geral, tendem para valores negativos. Os valores da sensação térmica sentidos pelos alunos estão muito próximos da sensação térmica prevista quando se aplica o índice
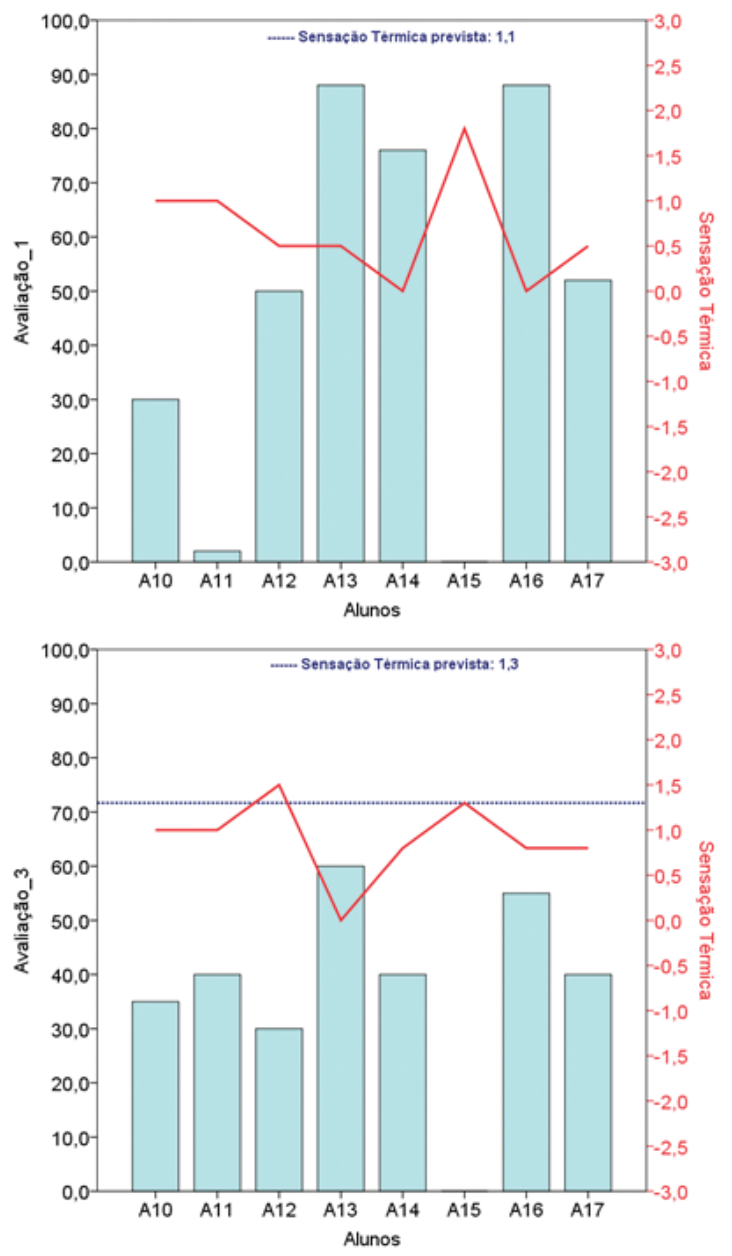

EsConTer. Quando se avalia para o valor previsto da sensação térmica o número de insatisfeitos, índice PPD, os resultados mostram que a Avaliação_1 e Avaliação_2 regista cerca de $30 \%$ de insatisfeitos, a Avaliação_3 e Avaliação_5 cerca de 40\% de insatisfeitos e a Avaliação_4 cerca de $10 \%$. Nestas circunstâncias os resultados obtidos mostram inequivocamente que o ambiente térmico de
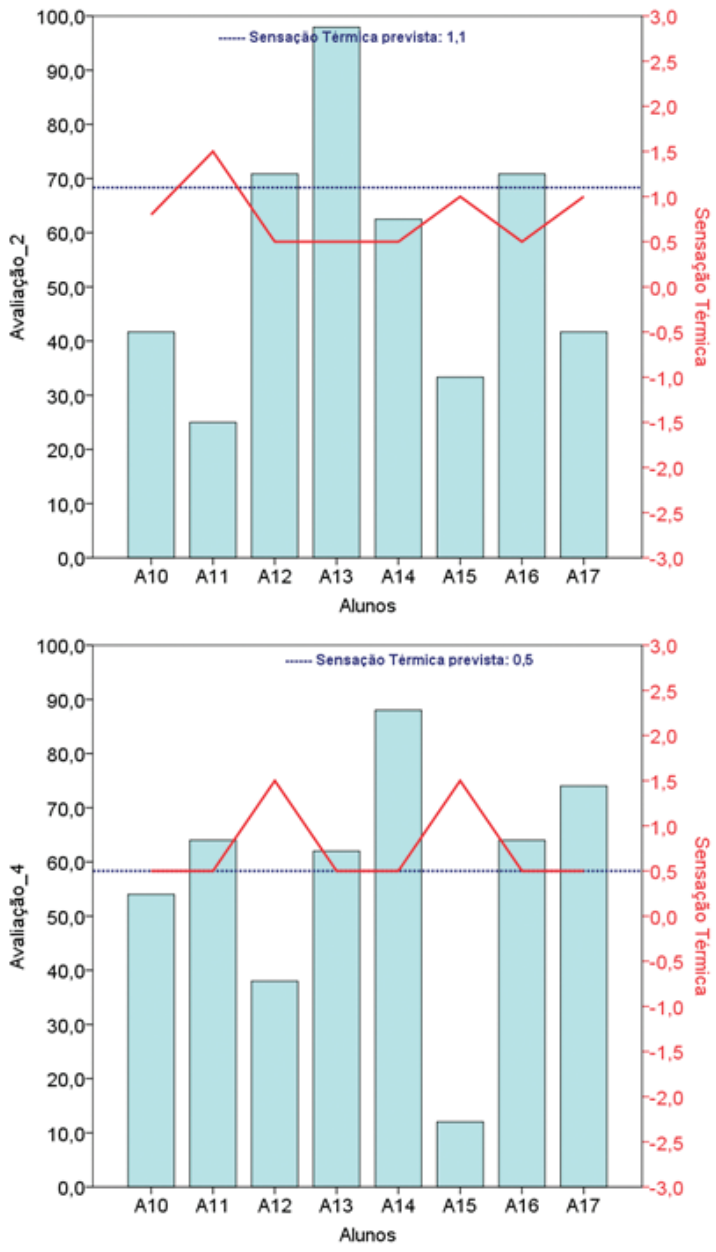

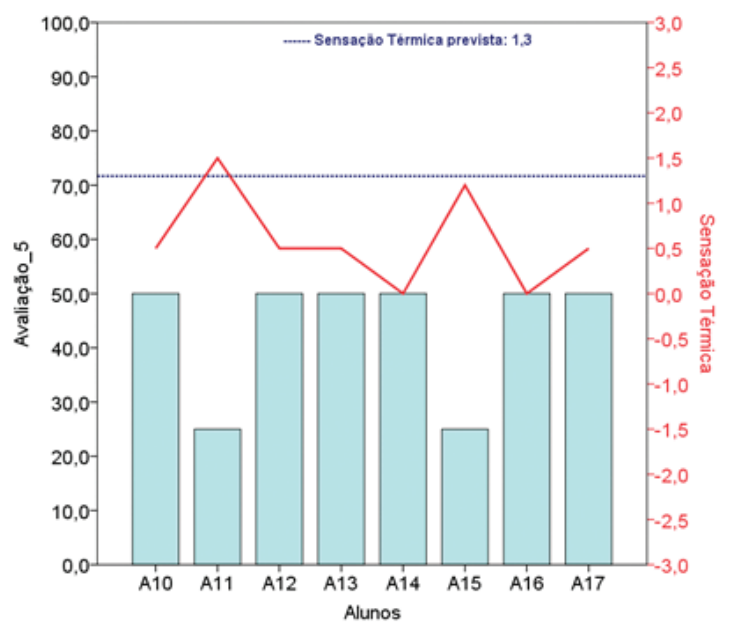

Fig. 5 - Avaliação e sensação térmica prevista e real, por aluno.

Fig. 5 - Evaluation and predicted and actual thermal sensation, per student. 
territorium 22


Fig. 6 - Sensação térmica "versus" avaliação do Aluno_A10 ao A17.

Fig . 6 - Thermal sensation "versus" assessment of Aluno_A10 to the A17. 
uma sala de aula condiciona o risco do desenvolvimento de competências e a aprendizagem. Neste trabalho foram realizadas apenas cinco avaliações.

Com base nos pressupostos apresentados e com base nos resultados obtidos é possível afirmar que a avaliação é fortemente condicionada pela sensação térmica sentida pelos alunos.

Assim, pode-se concluir que o processo de aprendizagem é afetado pelas condições térmicas do ambiente que rodeia os alunos. É importante salientar que nas avaliações realizadas os conteúdos avaliados foram lecionados na aula que se realizou a avaliação, o que reforça que, na maioria dos casos, os alunos não se encontravam em conforto térmico para a aquisição de conhecimentos.

No lado esquerdo da fig. 7 mostram-se os resultados para cada aluno em termos de avaliação. Há uma concordância de valores, entre os valores prévios, antes de aplicar esta metodologia para se conhecer o risco da construção do conhecimento para ambiente considerado de quente, e os valores registados durante o estudo. No lado direito da fig. 7, mostram-se os resultados da sensação térmica sentida pelos alunos em face da sensação térmica prevista pelo índice EsConTer. A observação dos resultados mostra inequivocamente que o EsConTer é um excelente preditor da sensação térmica sentida pelos alunos e que deve ser valorizado em estudos futuros.

A análise dos resultados mostra, inequivocamente, que a estratégia adotada neste estudo é uma ferramenta importante para avaliar como situações de desconforto térmico podem suscitar o risco do processo de aprendizagem de alunos.

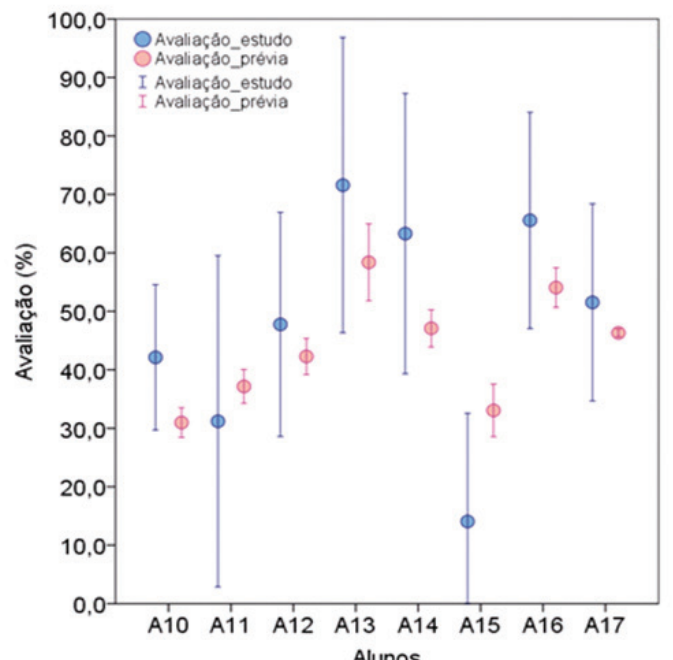

(a)

\section{Conclusão}

O estudo contribuiu para o desenvolvimento de conhecimento didático sobre a temática energia e ambiente térmico, promovendo sempre que possível a utilização de estratégias de aprendizagem ativas e de um elemento integrador, numa perspetiva de investigação-ação.

No geral, os alunos tiveram a oportunidade de concluir que a avaliação de conhecimentos adquiridos por eles é condicionada pela sensação térmica sentida para ambientes térmicos considerados de quentes.

Os resultados obtidos permitiram conhecer que há um patamar de risco para as sensações térmicas sentidas pelos alunos e, esta situação, parece condicionar um risco para o desenvolvimento de competências e a aprendizagem.

A análise de resultados mostrou que quando os valores da sensação térmica sentida pelos alunos é inferior a $-0,5$, ou superior a +0,5 da escala térmica sétima de cores, os resultados obtidos da avaliação de conhecimentos tendem a ser negativos, ou seja, inferiores a $50 \%$ (out $100 \%$ ). No entanto, quando a sensação térmica sentida pelos alunos se localiza na zona, considerada de conforto térmico ou seja entre os valores da escala térmica de $-0,5$ e $+0,5$, os resultados são, no geral, positivos, o que confirma que o resultado das avaliações de conhecimentos para os alunos envolvidos no estudo parece depender das caraterísticas termohigrométricas do ambiente térmico. Foi possível ainda constatar que quando a sensação térmica sentida pelos alunos regista valores altos com tendência a "quente" $(+2)$ os resultados obtidos pelos alunos são, no geral, bastante negativos.

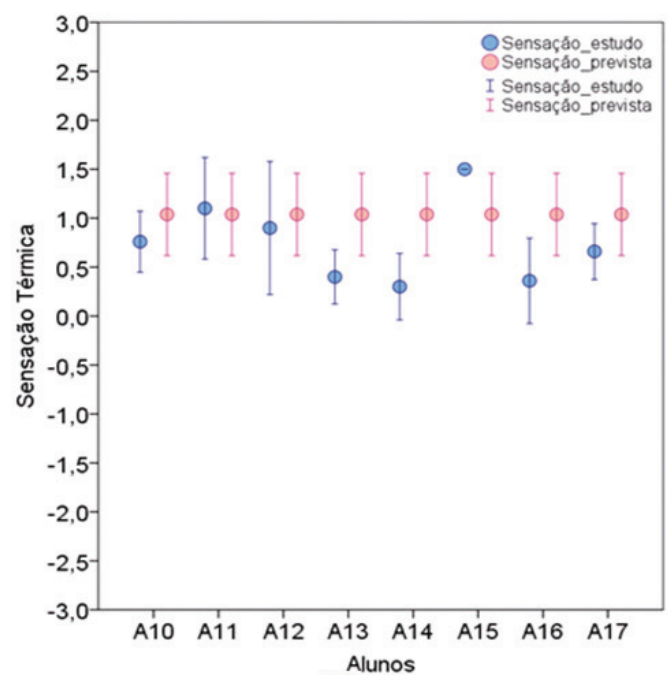

(b)

Fig. 7 - Avaliação estudo e avaliação prévia com os respetivos desvios da turma (A); Sensação térmica apresentada pelos alunos e sensação térmica prevista com os respetivos desvios da turma (b).

Fig. 7 - Evaluation study and preliminary evaluation with the respective deviations of the class (a); Thermal sensation presented by students and thermal sensation predicted with the respective deviation of the class (b). 
Ao avaliar-se o grau de insatisfação previsto para cada ambiente térmico quando se usou o índice EsConTer, os resultados obtidos mostraram concordância com a sensação térmica sentida pelos alunos e registada na escala de sensação térmica de cores.

Os dados sugerem que o método usado é uma ferramenta importanteparaavaliarcomosituaçõesdedesconfortotérmico podem condicionar o risco do processo de aprendizagem.

Estudos desta natureza parecem ser oportunos quando hoje se vive a problemática do aquecimento global e se debate a problemática energética na vertente da melhoria do bem-estar, fadiga e índices de produtividade intelectual.

\section{Agradecimentos}

O Este trabalho é financiado pela FCT/MEC através de fundos nacionais (PIDDAC) e cofinanciado pelo FEDER através do COMPETE - Programa Operacional Fatores de Competitividade no âmbito do projeto PEst-C/CED/UI0194/2013.

\section{Bibliografia}

ASHRAE 55 (2004). Thermal environmental conditions for human occupancy. American Society of Heating, Refrigerating and Air-Conditioning Engineers. Atlanta: Ashrae.

Coll, C., Palacios, J., e Marchesi, A. (2005). Desenvolvimento Psicológico e Educação. Artmed: Porto Alegre.

Fanger, P. (1972). Thermal Comfort. 2 ${ }^{\mathrm{a}}$ Edição, McGrawHill, New-York.

Goldemberg, J. e Lucon, O. (2007). Energia e meio ambiente no Brasil. Estudos Avançados, 21(59), p. 7-20.

Howell, W. e Stramiler, C. S. (1981). The Contribution of Psychological Variables to the Prediction of Thermal Comfort Judgments in Real World Settings. ASHRAETransactions, 87(1), p.609-621.

ISO 7730 (2005). Ergonomics of the thermal environment - Analytical determination and interpretation of the thermal comfort using calculation of the PMV and PPD indices and local thermal comfort criteria. International Organization for Standardization, Genève, Switzerland.

Kruger, E., Dumke, E. e Michaloski, A. (2001). Sensação de Conforto Térmico: respostas dos Moradores da Vila Tecnológica de Curitiba. VI Encontro Nacional de Conforto no Ambiente Construído, Anais do VI ENCAC, São Pedro.

Markov, D. (2002). Practical Evaluation of the Thermal Comfort parameters. Annual International
Course: Ventilation and Indoor climate. Sofia, Bulgária, P. Stankov (Ed), p. 158-170.

Morgado M., Talaia M. e Teixeira L. (2015). Identification of most critical areas in an industrial inner space regarding thermal Comfort: Environmental ergonomics. Occupational Safety and Hygiene III. In Arezes et al. (Eds), SH02015. CRC Press, Taylor and Franchis Group, London, p. 187-191.

Nieuwolt, S. (1977). Tropical climatology: an introduction to the climates of the low latitudes. John Wiley: New York.

Nobrega, R. S. e Lemos, T. V. S. (2011). O microclima e o (des)conforto térmico em ambientes abertos na cidade do recife. Revista de Geografia (UFPE), 28(1), p. 93-109.

Nogueira, M. C. J. A. e Nogueira, J. S. (2003). Educação, meio ambiente e conforto térmico: caminhos que se cruzam. Revista Electrónica em Educação Ambiental, 10, p. 104-108.

Rebelo, A. Baptista, J. S e Diogo, M. T. (2008). Caracterização das condições de conforto térmico na FEUP. Proceedings CLME'2008 / II CEM. $5^{\circ}$ Congresso Luso - Moçambicano Eng ${ }^{a}$ $2^{\circ}$ Congresso de Eng ${ }^{a}$ de Moçambique. Maputo. Editores Gomes et al. ISBN: 978-972-8826-20-8. Edições INEGI. Artigo 11A009, 14 páginas

Souza, V. e Justi, R. (2011). Interlocuções possíveis entre linguagem e apropriação de conceitos científicos na perspectiva de uma estratégia de modelagem para a energia envolvida nas transformações química. Ensaio Pesquisa em Educação em Ciências, 13, (2). Brasil: Universidade Federal de Minas Gerais Minas Gerais, p. 31-46.

Talaia, M. (2013). Riscos no local de trabalho - ambiente térmico quente. Riscos naturais Antrópicos e Mistos. In Departamento de Geografia, Faculdade de Letras, Universidade de Coimbra (Ed.). Homenagem ao professor Fernando Rebelo, p. 555-567.

Talaia, M. Meles, B. e Teixeira, L. (2013). Evaluation of the Thermal Comfort in Workplaces - a Study in the Metalworking Industry. Occupational Safety and Hygiene. Editors Arezes et al. Taylor e Francis Group: London, p. 473-477.

Talaia, M. e Rodrigues, F. (2008). Conforto e Stress Térmico: Uma Avaliação em Ambiente Laboral. Proceedings CLME'2008 / II CEM. $5^{\circ}$ Congresso Luso - Moçambicano Eng ${ }^{a}$ e $2^{\circ}$ Congresso de $E{ }^{a}$ de Moçambique. Maputo. Editores Gomes et al. Edições INEGI. Artigo 11A020, 15 páginas. 
Talaia, M. e Simões, H. (2009). EsConTer: um índice de avaliação de ambiente térmico. In SometCuba, Sociedade Meteorologia de Cuba (Eds.). Proceedings of $V$ Congresso Cubano de Meteorologia, p. 1612-1626.

Tavares I., Talaia M. e Teixeira L. (2015). Thermal Comfort - worker perception in a codfish packaging industry. Occupational Safety and Hygiene III. In Arezes et al. (Eds), SHO2015. CRC Press, Taylor and Franchis Group, London, p. 245-249.
Tilbury, D. (2011). Education for Sustainable Development: An Expert Review of Processes and Learning. Paris: UNESCO.

Wyon, D. (2010). Thermal and air quality effects on the performance of schoolwork by children. Fonte: http: //web1.swegon.com/upload/ AirAcademy/Seminars/Documentation_2010/ Vilnius/David_Wyon.pdf 